\title{
THE CHARACTERIZATION OF ANODIC OXIDE LAYERS ON SELECTED BIO-COMPATIBLE TITANIUM ALLOYS
}

\author{
Jan KrČIL*, Vladimír Mára, Stanislav Krum, Jana Sobotová \\ Department of Materials Engineering, Faculty of Mechanical Engineering, Czech Technical University in \\ Prague, Karlovo náměstí 13, 12135 Prague 2, Czech Republic \\ * corresponding author: jan.krcil@fs.cvut.cz
}

\begin{abstract}
Oxide layers on titanium alloy surfaces have an influence on bio-compatibility and corrosion resistance. In order to improve them, properties of oxide layers are examined. The oxide layer can be prepared by different methods and under various conditions. This results in a creation of layers showing different composition, structure, properties, stability, adhesion and biocompatibility. In the presented paper, samples of three titanium alloys were used: Commercially Pure (CP) titanium grade 2, Ti6Al4V alloy and $\beta$-titanium alloy Ti-39 wt.\% Nb. Samples were anodically $\left(1 \mathrm{M} \mathrm{H}_{2} \mathrm{SO}_{4} / 100 \mathrm{~V} / 1\right.$ hour $)$ oxidized. Changes in surface colouration and roughness were observed. The thickness of oxide layers was measured using a scanning electron microscope (SEM). The SEM was then used for observation of the surface topography of oxidized samples. The chemical composition of the surface layers was defined by X-ray photoelectron spectroscopy (XPS).
\end{abstract}

KEYwORDS: titanium; niobium; TiNb; anodic oxidation; oxide layers; surfaces.

\section{INTRODUCTION}

There is a wide spectrum of materials used as biomaterials. Group of titanium alloys is one of the most prominent amongst them. Titanium alloys are used for a significant range of implants or tools because of their mechanical properties, corrosion resistance and biocompatibility. The last two parameters are strongly influenced by an oxide layer on titanium surfaces. The properties of an oxide layer are dependent on the substrate material, presence of an interlayer, method of preparation and its conditions, etc. [1] 3].

The characteristics of a biomaterial surface include the biological response. Surface attributes, such as chemical composition, free surface energy and surface morphology, are studied in order to understand the surface properties and behaviour. One of the most common biomaterials - Ti6Al4V alloy — may be a cause of health issues. Its oxide layer also contains, in low amounts, ions of $\mathrm{Al}$ and $\mathrm{V}$, which are released into a human body 3 . The newly developed titanium $\beta$ alloys exhibits better biocompatibility ensured by a low quantity of alloying elements ( $\mathrm{Nb}$ or $\mathrm{Ta}$ for example) present in the oxide layer [1, 4,7].

The excellent compatibility between the tissue, bone and titanium alloy is predominantly controlled by properties of its stable surface oxide layer [1]. Oxide layers can be prepared by many different methods. The most common, and probably the easiest, is a controlled oxidation. There are different methods: oxidation at elevated temperatures and in different chemical compounds and anodic oxidation (besides other methods). The different oxidation process (and its conditions) leads to diverse layers: differences in chemical composition, mechanical properties, struc- ture, etc. For example, the difference in a layer's structure can affect the stability, adhesion or biocompatibility of the layer. Some authors 8 ] note that the rutile structure is more suitable for cells of certain type, yet others [1] have remarked that the anatase structure is more suitable for human body in general 9 [12].

Next to the basic anodic oxidation, there also exists a modified process, which aims to create nano-structured surfaces (with pores or tubes in a nano-scale). The main method of producing nanotubes on a titanium surface is anodic oxidation in electrolyte consisting of mixed acid of $1 \mathrm{M} \mathrm{H}_{3} \mathrm{PO}_{4}$ and $0.4 \mathrm{wt} . \% \mathrm{HF}$ solution, or $1 \mathrm{M}\left(\mathrm{NH}_{4}\right)_{2} \mathrm{SO}_{4}$ with $0.25 \mathrm{M} \mathrm{NH}_{4} \mathrm{~F}$. Nanostructured surfaces are used because of a better cell adhesion and higher osseointegration [1, 13].

In this work, the oxide layers prepared by the anodic oxidation are compared. The oxide layers were prepared on samples from three titanium-based biomaterials: CP Ti grade 2, Ti6Al4V alloy and $\beta$ alloy Ti-39 wt.\% Nb (Ti39Nb). The goal is to form structured (ideally nanostructured but not in a form of nanotubes) oxide layers by using simple electrolyte and higher voltages. The inspiration was the article [10, where similar procedure was carried out only for $\mathrm{CP}$ titanium samples.

\section{EXPERIMENT}

Materials for the experiment were in form of rods (diameter $12 \mathrm{~mm}$ ). These rods were cut to cylindrical samples, each with a thickness of $\sim 3 \mathrm{~mm}$. The samples were mechanically ground (using $\mathrm{SiC}$ papers 


\begin{tabular}{|c|c|c|c|c|}
\hline \multirow[b]{2}{*}{ Sample } & \multirow{2}{*}{$\begin{array}{l}\text { Surface } \\
\text { colour }\end{array}$} & \multirow{2}{*}{$\begin{array}{c}\text { Layer } \\
\text { thickness }[\mu \mathrm{m}]\end{array}$} & \multicolumn{2}{|c|}{ Surface roughness $\mathrm{Ra}[\mu \mathrm{m}]$} \\
\hline & & & Untreated samples & Oxidized samples \\
\hline CP Ti grade 2 & grey & $\sim 0.4$ & 0.023 & 0.048 \\
\hline Ti6Al4V & golden & $\sim 4.0$ & 0.021 & 0.288 \\
\hline $\mathrm{Ti} 39 \mathrm{Nb}$ & greenish purple & $\sim 0.1-0.2$ & 0.024 & 0.177 \\
\hline
\end{tabular}

TABLE 1. The surface colour, the surface roughness and thickness of the oxide layer on oxidized CP Ti grade 2 , Ti6Al4V and Ti39Nb samples.
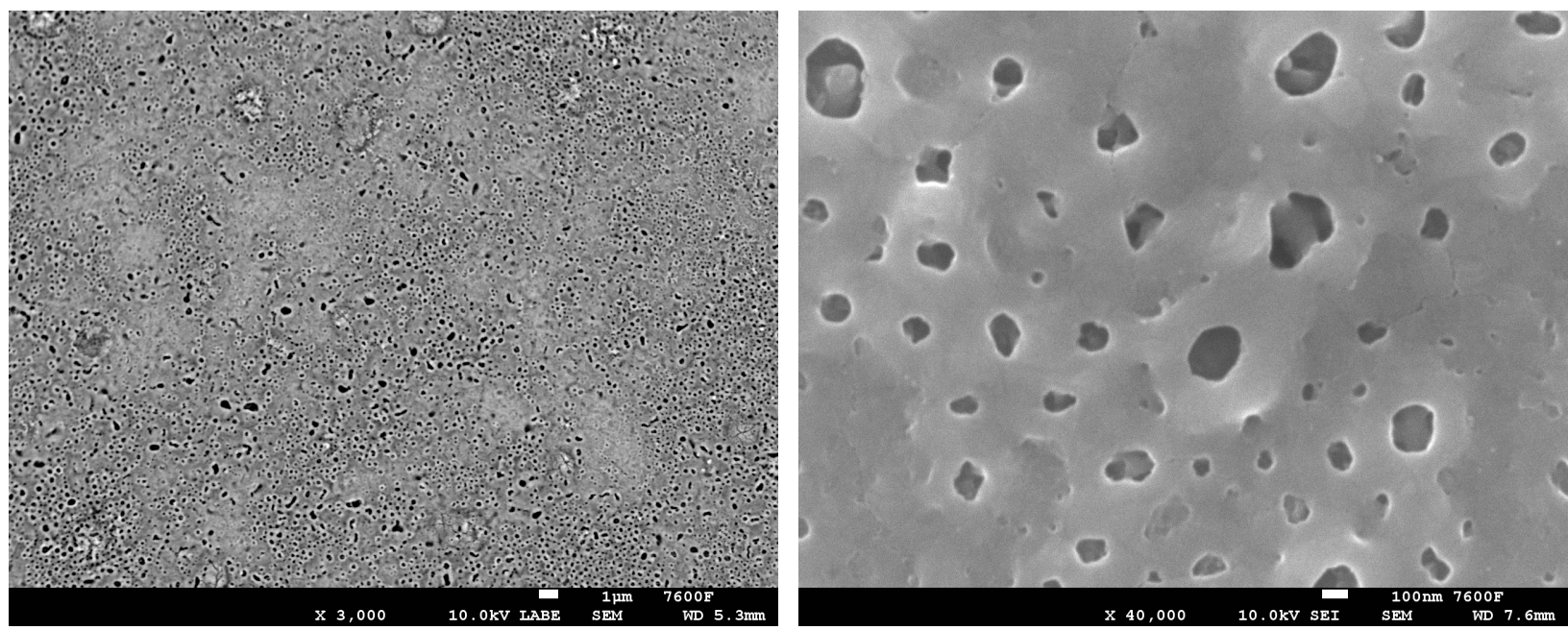

Figure 1. The overview (a) and the detail (b) of anodically oxidized surface of CP Ti grade 2 sample.

from grit P220 to grit P4000) and then polished (using neoprene cloth and $\mathrm{SiO}_{2}$ suspension mixed with $\mathrm{H}_{2} \mathrm{O}_{2}$ ) into mirror sheen.

Polished samples were anodically oxidized. The anodic oxidation was carried out at a room temperature in $1 \mathrm{M} \mathrm{H}_{2} \mathrm{SO}_{4}$. The electrolyte was in a custom made container and the circulation of the electrolyte was driven by compressed air; anodization was realized using platinum cathodes and the SZ 20 110/400, NES Nova Dubnica, SR power-source. Parameters of the oxidation were based on the article [11. The current was preset at app. $40 \mathrm{~mA} / \mathrm{cm}^{2}$ and the voltage at $\sim 100$ V. Samples were being oxidized for 1 hour, then cleaned and dried.

The change of surface colour was observed on oxidized samples. The surface roughness of the samples was measured using Hommel Tester T 1000 (Stylus tip $5 \mu \mathrm{m} / 90^{\circ}$; scanning length $5 \mathrm{~mm}$ ). Subsequently, the surface of samples was observed using the scanning electron microscope (SEM) Jeol JEM7600F. The SEM was also used to measure the thickness of oxide layers measured on cross-section samples. The qualitative and quantitative surface chemical analysis was acquired by X-ray photoelectron spectroscopy (XPS). The used spectrometer consists of UHV apparatus $\left(p \approx 10^{-7} \mathrm{~Pa}\right)$ with dual $(\mathrm{Al} / \mathrm{Mg}) \mathrm{X}$-ray tube and 5-channel Omicron hemispherical analyzer EA 125. $\mathrm{Al}$ anode (energy of radiation $1486.6 \mathrm{eV}$ ) was used in performed experiments. The surface element concentration was calculated by a relative sensitivity factor method.

\section{RESULTS}

The change of colour on the surface of oxidized samples is noted in Table 1 The table also contains the results of measuring the surface roughness and thickness of the oxide layers.

The colouration of the surface is distinct for every sample group, but within each group, the surface colour is constant. The surface colour is mostly affected by the thickness of the oxide layer, though in a smaller scale, the chemical composition of oxides can influence it as well.

The thickness of the oxide layer varied significantly between different groups of samples. The thickest layer was measured on the Ti6Al4V samples with a mean value of $\sim 4 \mu \mathrm{m}$. Oxide layers on the other two groups were significantly thinner, about $0.4 \mu \mathrm{m}$ for $\mathrm{CP} \mathrm{Ti}$ and just about $0.1-0.2 \mu \mathrm{m}$ for Ti39Nb. The layer is thicker in the areas with oxide crystals. Differences in thickness can be explained by the speed of passivation [11.

The noticeable change of the surface roughness, when compared to the polished surfaces (with $\mathrm{Ra} \approx$ $0.02 \mu \mathrm{m}$ ), was observed as well. But the trend in the change of the surface roughness was different from the one observed in the case of the oxide layer's thickness. The smallest surface roughness was found on the CP Ti samples, the roughest surface was found on the Ti6Al4V sample. This coincides with the results of the thickness measurement. The resulting values of the surface roughness of $\mathrm{TiNb}$ were found between 

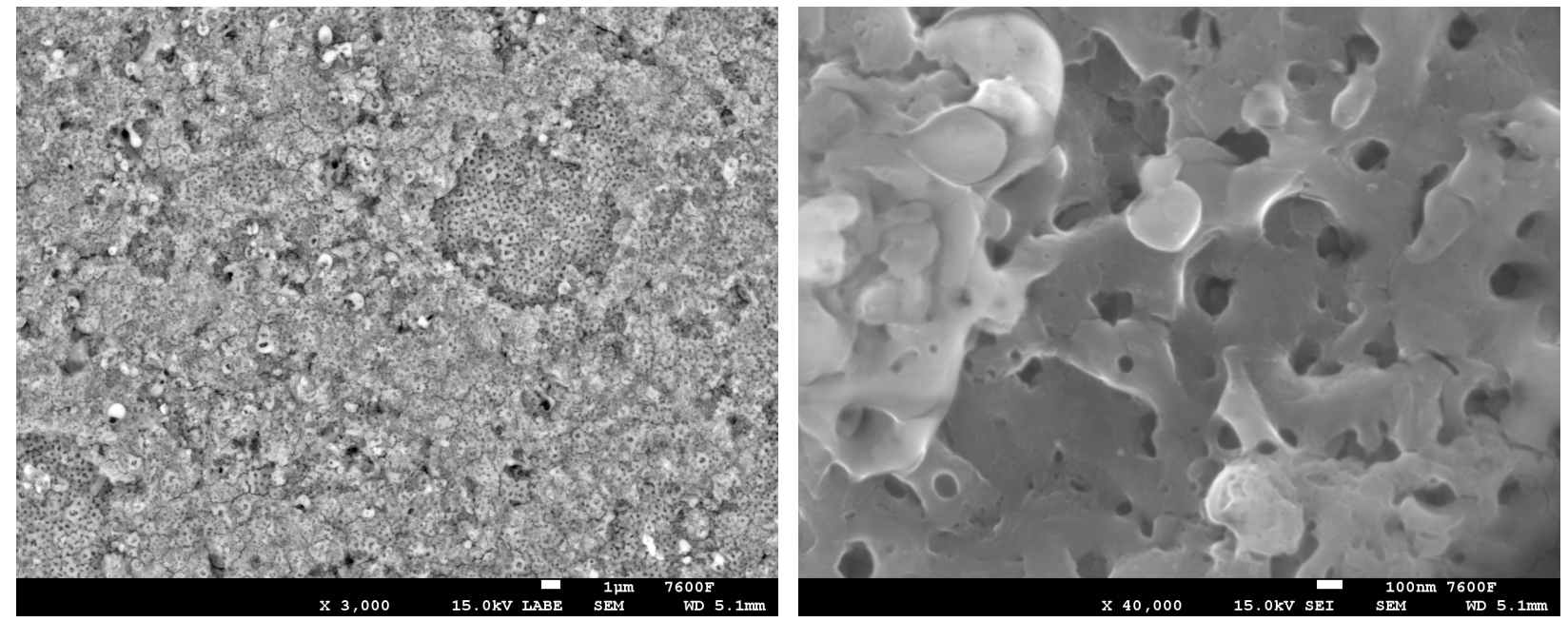

FiguRE 2. The overview (a) and the detail (b) of anodically oxidized surface of Ti6Al4V sample.

these two aforementioned values. The reason for these values may be found in the surface topography or the process of the oxide crystals growth, which is mentioned in the next part of the article.

\subsection{SURFACE TOPOGRAPHY}

The surface of the anodized CP Ti sample is in the Fig. 1. The overview (Fig. 17) shows that the whole surface is completely covered with an oxide layer. It is also possible to notice that the whole surface contains a specific structure. The detail (Fig. 1b) shows that the structure consists of pores. Diameter of these pores varies in a range between app. 50-300 nm. Both the overview and the detail are representative for the whole surface of the anodically oxidized CP Ti. The surface around pores seems relatively smooth. Since individual pores are relatively small in comparison to a testing needle tip, they would not significantly affect the roughness measurement.

The surface of the anodically oxidized Ti6Al4V sample (see Fig. 2) seems different, but some similarities are noticeable. The overview (Fig. 2 a) shows rough, coarse surface, which is completely covered with oxides. The uniformity of the surface layer is disturbed by a presence of several craters. But, similarly to the oxide layer on $\mathrm{CP} \mathrm{Ti}$, the surface has the substructure containing pores. These pores are about the same size as on CP Ti. The pores are more distinctive inside the craters. This fact is documented in the Fig. $2 \mathrm{~b}$. The detail shows a complex 3-dimensional porous substructure. The higher surface roughness is due to the coarse surface and is, moreover, accented by the presence of the craters. Again, a coarse, rough surface is caused by the higher thickness of this particular oxide layer.

The surface of anodically oxidized Ti39Nb (Fig. 3) shows some resemblance to the two previous samples but, in general, differs. The first significant difference can be seen in an overview (Fig. 3a): the surface is not completely covered with a uniform oxide layer. Oxide crystals are the dominant feature of the surface, they

\begin{tabular}{lcrccccc}
\hline Sample & $\mathrm{O}$ & $\mathrm{O}_{\mathrm{C}}$ & $\mathrm{Ti}$ & $\mathrm{Al}$ & $\mathrm{V}$ & $\mathrm{Nb}$ & $\mathrm{C}$ \\
\hline CP Ti grade 2 & 51 & 10 & 27 & - & - & - & 12 \\
Ti6Al4V & 53 & 9 & 23 & 3 & 2 & - & 10 \\
Ti39Nb & 44 & 13 & 16 & - & - & 6 & 21 \\
\hline
\end{tabular}

TABLE 2. Surface chemical concentration of $\mathrm{Ti}$, Ti6Al4V and TiNb samples after oxidation, in at.\%.

appear in individual clusters and their distribution seems random at first. Theoretically, islands/clusters of oxide crystals should be growing on microstructural grains of certain orientations. But this has yet to be proven by the electron backscatter diffraction (EBSD). Under and around the oxide clusters, the background is visible (the detail is shown in the Fig. $3 \mathrm{~b}$ ), which seems to have a substructure similar to the anodically oxidized CP Ti and Ti6Al4V. Pores are vague, yet visible; their size is again similar to the ones on previous samples. But overall, the background layer seems to be very thin. The higher surface roughness can be explained, even though the oxide layer is very thin, by the coarse, cluster-like formations of oxide crystals on the relatively smooth background. The adhesion of oxide clusters was not exactly measured.

\subsection{Chemical COMPOSITION OF THE SURFACE}

The results of XPS surface chemical analysis are shown in the Table 2

The analysis shows that surfaces of all samples are mostly composed of $\mathrm{TiO}_{2}$. The compound is determined from core levels of $\mathrm{Ti} 2 \mathrm{p}$ at $458.8 \mathrm{eV}\left(\mathrm{Ti}^{+\mathrm{IV}}\right)$ and $\mathrm{O}$ 1s at $530.1 \mathrm{eV}$ (O-Ti bond). For TiNb samples, $\mathrm{Nb}$ is in $\mathrm{Nb}^{+\mathrm{V}}$ state $(\mathrm{Nb} 3 \mathrm{~d}$ at $207.2 \mathrm{eV}$ ).

Anodically oxidized Ti6Al4V features lower oxidation states: $29 \%$ of $\mathrm{Ti}$ is in lower oxides ( $2 \mathrm{p}$ between $457.2 \mathrm{eV}$ and $456.0 \mathrm{eV}), \mathrm{Al}$ is in lower oxide (2s at $118.1 \mathrm{eV})$ and metallic alloy $(116.1 \mathrm{eV})$ and $\mathrm{V}$ remains in fully oxidized $\mathrm{V}^{+\mathrm{V}}$. 

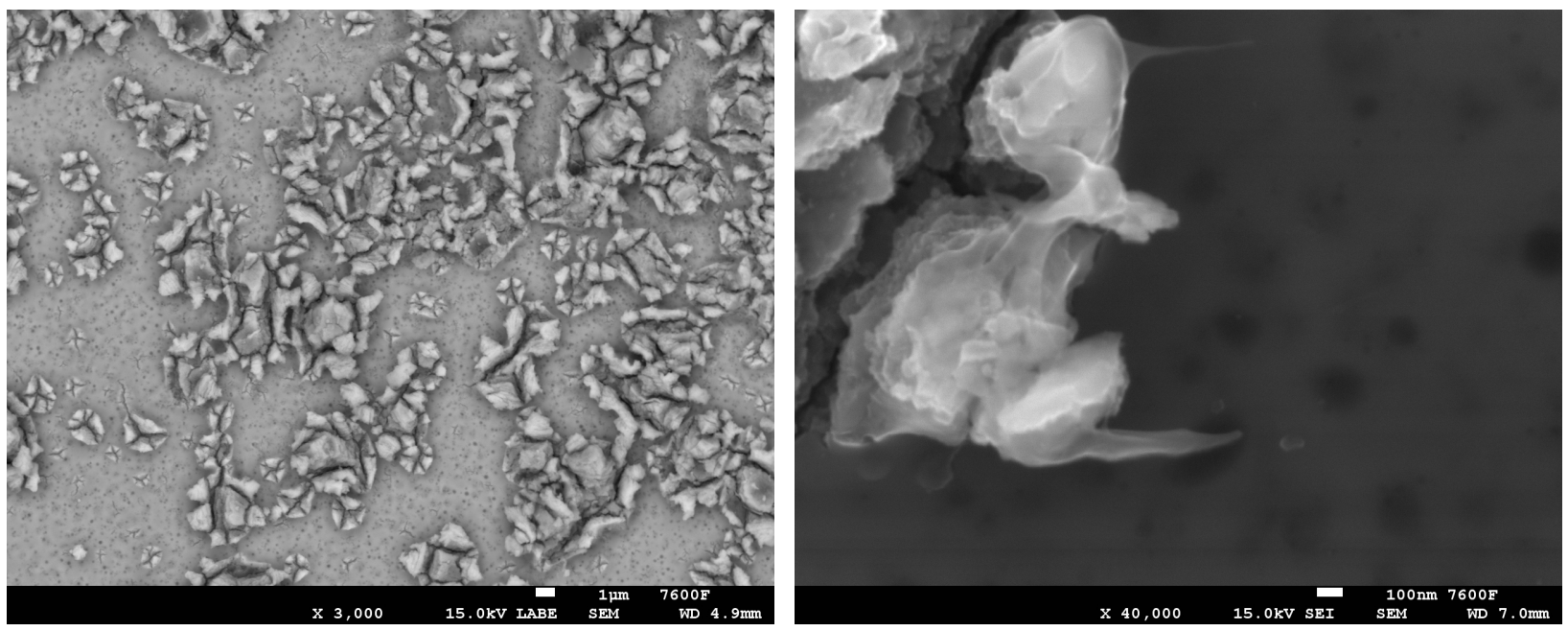

Figure 3. The overview (a) and the detail (b) of anodically oxidized surface of Ti39Nb sample.

The oxygen concentration is differentiated according to its origin. $\mathrm{O}$ denotes the contribution of $\mathrm{Ti}, \mathrm{Nb}$ and $\mathrm{V}$ oxides and $\mathrm{O}_{\mathrm{C}}$ marks the contaminants. However, the $\mathrm{Al}$ oxide contribution cannot be distinguished from contaminants due to their similar binding energies and it is, therefore, included in $\mathrm{O}_{\mathrm{C}}$.

The composition of the oxide layer dependent on the depth from surface to substrate is different. The surface contains higher amount of $\mathrm{O}$, while concentration of $\mathrm{Ti}$ (and possible alloying elements) near the interface between the substrate material and oxide layer will be higher.

\section{Discussion}

Combined results show differences of samples oxidized in the same conditions. However, there is a visible trend for all of the samples. There seems to be a relation between the surface roughness and other properties: layer thickness and surface topography. Both of them are affected not only by the oxidation process itself and the chemical composition of the oxidized materials but also by the different crystallographic orientation of microstructural grains. However, this has to be proven by other experimental method, most likely by the EBSD analysis.

The chemical composition of $\mathrm{Ti}$ samples consists solely of $\mathrm{TiO}_{2}$. In case of $\mathrm{Ti} 6 \mathrm{Al} 4 \mathrm{~V}$ alloy, the sample exhibits slightly increased concentration of $\mathrm{Al}$ and $\mathrm{V}$. The surface composition of TiNb sample contains roughly $6 \% \mathrm{Nb}$, which is significantly lower than its volume concentration $(39 \%)$. However, the presence of $\mathrm{Nb}$ in the surface layer is in accordance with the theory [1, 10] and should be the cause of a better biocompatibility because of $\mathrm{Nb}$ being more biocompatible than Ti. Moreover, the better biocompatibility originates also from the presence of $\mathrm{Nb}$ (mostly as substituting atoms in $\mathrm{Ti}$ oxides) in the surface layer [4.

The anodic oxidation of $\mathrm{CP}$ Ti resulted in a relatively smooth oxide layer with a medium thickness (close to the commercially used values [1]) and porous substructure. Ti6Al4V samples show similar results, but the layer is significantly thicker and rougher. The porous substructure is present as well (with approximately the same size of the pores), but pores are more distinct in craters in the surface layer. The Ti39Nb alloy exhibits slightly different results. The layer is relatively thin, yet the surface roughness is higher as a result of the surface topography - clusters of oxide crystals on top of the thin layer showing signs of porous substructure. Oxide crystals are possibly following certain crystallographic orientations of microstructural grains.

The observation of the surface shows that there exists a substructure in the oxide layer on all samples, though there are differences. The results show the porous nanostructure on the surface of oxidized samples, even though the nanostructure is usually achieved by more complex methods [1, 13].

In further experiments, it would be appropriate to widen the range of materials and oxidation parameters to evaluate the effect on the surface layer and whether it is a possibility to obtain a different nanostructure or to prepare this nanostructure on thin layers of titanium alloys.

\section{Conclusions}

The anodic oxidation resulted in a formation of oxide layers on all samples from all tested groups. The existence of a layer was observed immediately after the oxidation process because of the colouration of the samples' surfaces.

The change of thee surface and its properties was then verified by measuring the roughness, thickness of oxide layer and its chemical composition. The topography of the surface was observed as well. A similar pattern was observed on the changes of the thickness, roughness and surface topography. Higher roughness correlating to thicker and/or more structured layers.

In the case of $\mathrm{CP} \mathrm{Ti}$ and $\mathrm{Ti} 6 \mathrm{Al} 4 \mathrm{~V}$, the surface was covered with a uniform oxide layer, even though 
the thickness of Ti6Al4V oxide layer was 10 times higher than that on $\mathrm{CP}$ Ti. Both of the layers exhibited the porous substructure. Although Ti39Nb samples showed signs of the similar substructure, the predominant structure was made of clusters of oxides affecting the roughness. The Ti39Nb oxide layer was the thinnest of the three as well.

The cluster-like oxide crystals formation on the surface of Ti39Nb seems to be following certain crystallographic orientations of microstructural grains. This should be examined by the EBSD measurement in future.

The surface of all materials consists primarily of $\mathrm{TiO}_{2}$. Even the $\mathrm{Ti} 39 \mathrm{Nb}$ surface has only about $6 \% \mathrm{Nb}$. In the case of $\mathrm{CP} \mathrm{Ti}$, Ti6Al4V and $\mathrm{Ti} 39 \mathrm{Nb}$, the chemical composition of oxide is almost identical.

For further studies, it would be appropriate to cover a wider range of oxidation parameters to see the differences of the resulting layers.

\section{ACKNOWLEDGEMENTS}

This work was supported by the Grant Agency of the Czech Republic (grant 15-01558S) and by the Ministry of Education, Youth and Sport of the Czech Republic, program NPU1, project LO1207.

\section{REFERENCES}

[1] O. Yoshiki: Bioscience and bioengineering of titanium materials, Elsevier, London 2013. DOI:10.1016/b978-0-08-045142-8.x5000-2

[2] F. Zhang, E. Burkel: In: Biomedical Engineering, Trends in Materials Science, Ed.: A. Laskovski, 2010, pp. 203-224. DOI:10.5772/12874

[3] Zdeněk Tolde, Vladimír Starý, Ladislav Cvrček, Marta Vandrovcová, Jan Remsa, Stanislav Daniš, Jan Krčil, Lucie Bačáková, Petr Špatenka: Materials Science and
Engineering C 80 (2017) 652-658. DOI:10.1016/j.msec.2017.07.013

[4] I. Jirka, M. Vandrovcová, O. Frank, Z. Tolde, J. Plšek, T. Luxbacher, L. Bačáková, V. Starý: Mater. Sci. Eng. C Mater. Biol. Appl. 33(3) (2013) 1636-1645. DOI:10.1016/j.msec.2012.12.073

[5] R. Godley, D. Starosvetsky, I. Gotman: Sci.Mater. Med. 17 (2006) 63-67. DOI:10.1007/s10856-006-6330-6

[6] M. Niinomi, M. Nakai, J. Hieda: Acta Biomater. 8 (11) (2012) 3888-3903. DOI:10.1016/j.actbio.2012.06.037

[7] P. Vlcak, J.Drahokoupil, P. Vertat, J. Sepitka, J. Duchon: Journal of Alloys and Compounds, 746 (2018) 490-495. DOI:10.1016/j.jallcom.2018.02.30

[8] T. de P. Busquim, C.N. Elias, J.E. May, S.E. Kuri, P.A. de P. Nascente: In: Medical device materials: proceedings of the Materials and Processes for Medical Devices Conference, Ed: J. Gilbert, 2009, pp. 60-69.

[9] C. Sittig, M. Textor, ND. Spencer, M. Wieland, P-H. Vallotton: J Mater Sci Mater Med 10 (1999) 35-46. DOI:10.1023/a:1008840026907

[10] M. Metikoš-Huković, M. Ceraj-Cerić: Surf Technol 24 (1985) 273-283. DOI:10.1016/0376-4583(85)90077-9

[11] X. Cui, H-M. Kim, M. Kawashita, L. Wang, L. Xiong, T. Kokubo, et al.: Dent Mat 25 (2009) 80-86. DOI:10.1016/j.dental.2008.04.012

[12] G. Zorn, A. Lesman, I. Gotman: Surf. Coat. Technol. 201(3-4) (2006) 612-618. DOI:10.1016/j.surfcoat.2005.12.009

[13] IH. Bae, KD. Yun, HS. Kim, BC. Jeong, HP. Lim, SW. Park, et al.: J Biomed Mater Res B Appl Biomater 93 (2010) 484-491. DOI:10.1002/jbm.b.31606

[14] AC. Fraker, AW. Ruff: Titanium science and technology, vol. 4. New York, NY: Plenum Press; 1973. pp. 2447-2457. DOI:10.1007/BF03354319 